\title{
Aprendizagem Colaborativa no Ensino Médio por meio de Gamificação: Um Relato de Experiência
}

\author{
Jamille Silva Madureira ${ }^{1}$, Aline de Jesus Sá ${ }^{1}$, Carlos Mariano Melo Junior ${ }^{1}$, \\ Elaine Meneses Souza Lima ${ }^{1}$, Giovanni Gomes Lessa ${ }^{1}$, José Hélio Barbosa Junior ${ }^{1}$, \\ Tiago Barbosa da Silva ${ }^{1}$, Tiago Cordeiro de Oliveira ${ }^{1}$ \\ ${ }^{1}$ Instituto Federal de Sergipe (IFS) - Campus Estância \\ Rua Café Filho, n 260, Bairro Cidade Nova - Estância - SE - Brasil \\ \{jamille.madureira, aline.sa, carlos.melo, elaine.lima, \\ giovanni.lessa, helio.junior, tiago.silva, tiago.cordeiro\}eifs.edu.br
}

\begin{abstract}
This paper reports an experience of gamification as an interdisciplinary activity between computer classes and other subjects in the first year of the an integrated seconday-level technical course. The group was divided into teams, which were responsible for preparing the games in a quiz format using a presentation editor tool and Scratch. At the end of the activity, the students reported that the experience was positive, as they had the opportunity to learn the contents of the subjects by developing their creativity and their teamwork skills.
\end{abstract}

Resumo. Este artigo relata uma experiência de gamificação como atividade interdisciplinar entre as aulas de informática e demais disciplinas do primeiro ano de um curso integrado ao ensino médio. A turma foi dividida em grupos, que ficaram responsáveis pela elaboração dos jogos em formato de quiz utilizando uma ferramenta de editor de apresentação e o Scratch. Ao final da atividade, os alunos relataram que a experiência foi positiva, pois tiveram a oportunidade de aprender os conteúdos das disciplinas desenvolvendo a criatividade e trabalhando em grupo.

\section{Introdução}

Para que se faça uso de todos os benefícios que as TDIC (Tecnologias Digitais de Informação e Comunicação) podem proporcionar na educação, é necessária uma mudança na prática educacional, transformando-a em um processo mais colaborativo. Nesse novo cenário, a prioridade são os aprendizes, que devem ser estimulados a se tornarem indivíduos cooperativos, autônomos, críticos, colaborativos, criativos, dinâmicos, que saibam trabalhar em grupo e enfrentar os desafios constantes na era do conhecimento [Morin 2000],[Schneider 2013].

A aprendizagem colaborativa defende a ideia de que o aluno deve ser um elemento ativo no processo de aprendizagem, permitindo a ele possibilidades de desenvolvimento de competências sociais e cognitivas. A aprendizagem é favorecida quando os alunos são inseridos em um projeto de construção colaborativa, no qual podem se posicionar em relação ao que está sendo construído e são orientados a dividir o espaço com os colegas. Assim, professores e alunos terão o seu tempo para refletir sobre ideias coletivas produzidas no processo de ensino-aprendizagem. [Bittencourt et al. 2004]. 
Nesse contexto, há um crescente incentivo ao uso de metodologias ativas de ensino e aprendizagem que pode abrir portas a um maior engajamento dos alunos como protagonistas do processo [Wiener and de Campos 2019]. Como metodologia ativa, pode-se citar os jogos didáticos ou jogos sérios, que tem a finalidade de favorecer a aprendizagem e não somente o entretenimento. Assim, surgem a GBL (Game Based Learning ou Aprendizagem Baseada em Games) e como proposta de educação, surge a gamificação [Coutinho 2019].

A Aprendizagem Colaborativa com Suporte Computacional (Computer Supported Collaborative Learning - CSCL) tem como objetivo o desenvolvimento de softwares que proporcionem a aprendizagem em grupo, oferecendo atividades criativas de exploração intelectual e interação social, atuando como mediação entre os membros do grupo [Oliveira et al. 2019].

Ao que se refere ao uso de gamificação em sala de aula, um dos maiores desafios reside em fazer com que os elementos de jogos potencializem o aprendizado e não fiquem restritos apenas ao entretenimento [Wiener and de Campos 2018]. O quiz é um exemplo de jogo digital educacional, constituído de perguntas em que o jogador avança ao acertar a resposta. Pode ser utilizado no espaço escolar, pois são capazes de auxiliar a aprendizagem de maneira significativa e lúdica, motivando a ação dos estudantes [Alves et al. 2015].

A importância da interdisciplinaridade no ensino básico está na inovação e no estabelecimento de práticas de ações coletivas dos docentes no processo educativo, que podem servir como estratégia de combate a evasão [Terradas 2019]. Desta maneira, este projeto interdisciplinar teve como objetivo incentivar a aprendizagem dos alunos por meio de uma atividade em que os mesmos pudessem desenvolver o conhecimento de maneira lúdica, criativa e em colaboração com os colegas, buscando um maior engajamento durante as aulas.

O presente artigo relata a experiência do desenvolvimento de jogos para auxílio do processo de ensino-aprendizagem em turmas do primeiro ano de Curso Técnico Integrado ao Ensino Médio em Edificações, durante três anos, conduzida entre 2017 e 2019. Os alunos desenvolveram jogos em formato de quiz com conteúdos abordados em sala de aula por seis disciplinas do currículo. No primeiro ano do referido curso, a matriz curricular é composta por quinze disciplinas, em um total de trinta e três aulas semanais. A fim de evitar o excesso de atividades e conteúdos, este projeto teve como princípio norteador a interdisciplinaridade.

\section{Materiais e métodos}

O projeto foi realizado durante três anos (2017-2019) em turmas ingressantes do Curso Técnico Integrado ao Ensino Médio em Edificações. Para a criação dos jogos, duas ferramentas foram utilizadas: o editor de apresentação Google Apresentações e a linguagem de programação Scratch, sendo esta utilizada apenas no ano de 2019, por demanda dos alunos participantes do projeto.

\subsection{Google Apresentações}

Essa ferramenta foi utilizada nos três anos do projeto. A atividade foi planejada com carga horária de vinte horas, divididas em dez encontros durante as aulas de Informática 
Básica no laboratório da escola.

No primeiro encontro, o projeto foi apresentado aos alunos, especificando as disciplinas envolvidas, quantidade de questões e possíveis interações no jogo. A turma foi dividida em grupos de quatro componentes, sendo permitido que os próprios alunos escolhessem com quem gostariam de desenvolver o projeto. As aulas dedicadas ao projeto foram executadas conforme apresentado na Tabela 1.

Tabela 1. Execução do projeto com a ferramenta Google Apresentações

\begin{tabular}{|c|c|}
\hline Aula & Atividade \\
\hline 01 & Apresentação do projeto e definição das equipes \\
\hline 02 & Apresentação da ferramenta Google Apresentações \\
\hline 03 a 09 & Elaboração dos jogos \\
\hline 10 & Apresentação dos quizzes \\
\hline
\end{tabular}

Das dezessete disciplinas do currículo, cinco fizeram parte do projeto: Biologia, Inglês, Física e Química (Base Nacional Comum Curricular) e Desenho Técnico (Núcleo Profissionalizante). Os professores dessas disciplinas ficaram responsáveis por sugerir os assuntos que seriam abordados no jogo. Para evitar dificuldade na elaboração das questões, foi determinado que os jogos deveriam envolver assuntos que já tinham sido finalizados com a turma. Ficou definido que os jogos teriam cinco questões sobre conteúdos de cada disciplina, totalizando vinte e cinco perguntas.

Para a criação dos quizzes, os alunos utilizaram a internet para pesquisa e o editor online Google Apresentações para elaboração do quiz. Essa ferramenta foi escolhida por ser gratuita, os arquivos ficam salvos na nuvem (evitando a perda do documento), além de permitir o compartilhamento de arquivo para colaboração, o que é fundamental nesse projeto, visto que o jogo foi desenvolvido em grupo.

As perguntas foram elaboradas sob supervisão dos professores das disciplinas envolvidas, que avaliaram se as questões eram claras e se as opções de respostas eram apropriadas para as perguntas. No decorrer das aulas de informática, os alunos desenvolveram os quizzes realizando atividades como: pesquisa sobre os conteúdos e imagens que pudessem ser usadas nos jogos, edição de imagens, configuração de layout e hiperlinks.

\subsection{Scratch}

A linguagem Scratch foi escolhida por ser uma ferramenta lúdica para o aprendizado de programação, já que utiliza blocos que substituem as linhas de códigos escritas em uma linguagem de programação usual. Assim, os alunos puderam focar no aprendizado da lógica e na construção dos jogos, sem se preocupar com erros de sintaxe, comuns em linguagens de programação textuais.

Essa ferramenta foi utilizada apenas no ano de 2019. A atividade foi planejada com carga horária de vinte e quatro horas, divididas em doze encontros durante as aulas de Informática Básica no laboratório da escola.

No primeiro encontro, foi apresentado o projeto aos alunos, especificando a disciplina e conteúdo abordado e quantidade de questões. A turma foi dividida em duplas, aplicando conceitos da metodologia de desenvolvimento em pares. As demais aulas fo- 
ram utilizadas para o ensino da ferramenta e elaboração do jogo, como descrito na Tabela 2, mais abaixo.

Como os alunos nunca tiveram contato com programação anteriormente, apenas uma disciplina foi escolhida para participar do projeto com o Scratch. A selecionada foi a Matemática, visto que há uma melhor integração entre os conteúdos. O professor desta disciplina ficou responsável pela escolha dos conteúdos que seriam abordados. Assim, ficou definido que os jogos deveriam conter três questões sobre equações do segundo grau e três questões sobre trigonometria no triângulo retângulo, totalizando seis questões.

Tabela 2. Execução da etapa Scratch do projeto

\begin{tabular}{|c|c|}
\hline Aula & Atividade \\
\hline 01 & Apresentação do projeto e definição das duplas \\
\hline 02 & Scratch: apresentação da linguagem e conceitos de algoritmos \\
\hline 03 & Scratch: algoritmos sequenciais \\
\hline 04 & Scratch: estrutura de decisão \\
\hline 05 & Scratch: estrutura de repetição \\
\hline 06 & Scratch: configuração de personagens e cenários \\
\hline 07 & Scratch: broadcasting de mensagens e configuração de tentativas \\
\hline 08 a 11 & Elaboração dos jogos \\
\hline 12 & Apresentação dos jogos \\
\hline
\end{tabular}

Para a criação dos quizzes, os alunos utilizaram as listas de exercícios que já tinham sido estudadas em sala de aula. As perguntas foram adaptadas ao jogo sob a supervisão do professor de matemática.

\subsection{Método de avaliação}

A avaliação foi realizada por todos os docentes envolvidos no projeto, por meio de critérios qualitativos. Foi considerado o desempenho individual dos alunos durante o desenvolvimento do projeto e o jogo produzido pela equipe. Os critérios utilizados são apresentados na Tabela 3.

Tabela 3. Critérios de avaliação

\begin{tabular}{|c|c|}
\hline Jogos & Alunos \\
\hline Perguntas de fácil compreensão & Participação nas aulas \\
\hline Criatividade e inovação & Engajamento com o projeto \\
\hline $\begin{array}{c}\text { Perguntas integradas e } \\
\text { contextualizadas com o curso }\end{array}$ & $\begin{array}{c}\text { Interação com os colegas e } \\
\text { professores }\end{array}$ \\
\hline $\begin{array}{c}\text { Visualização das perguntas } \\
\text { (harmonia entre fundo, fonte, } \\
\text { cores) }\end{array}$ & $\begin{array}{c}\text { Desenvoltura durante a } \\
\text { apresentação do jogo didático }\end{array}$ \\
\hline
\end{tabular}

Com a finalidade de registrar e calcular as notas, foi criado um documento no Google Planilhas, no qual os professores registraram as notas e a ferramenta calculou automaticamente a média aritmética de cada aluno.

\section{Resultados e discussão}

Ao longo de três anos, noventa alunos com a idade média de quinze anos participaram do projeto, conforme apresentado na Tabela 4, a seguir. 
IX Congresso Brasileiro de Informática na Educação (CBIE 2020)

Anais do XXXI Simpósio Brasileiro de Informática na Educação (SBIE 2020)

Tabela 4. Alunos participantes por ano e sexo

\begin{tabular}{|c|c|c|c|}
\hline Ano & Masculino & Feminino & Total \\
\hline 2017 & 17 & 14 & 31 \\
\hline 2018 & 13 & 18 & 31 \\
\hline 2019 & 15 & 13 & 28 \\
\hline Total & 45 & 45 & 90 \\
\hline
\end{tabular}

Durante a execução do projeto em 2019, foi possível perceber que os alunos tinham interesse de incrementar os jogos, demonstrando insatisfação com algumas limitações do editor de apresentação. Assim, surgiu a ideia de desenvolver um novo projeto utilizando o Scratch.

\subsection{Google Apresentações}

Para a elaboração das perguntas, foram priorizados conteúdos que os docentes já haviam trabalhado em sala de aula, para que os alunos tivessem um conhecimento prévio para a construção das questões. Após a aprovação pelo professor da disciplina, a próxima atividade foi inserir as questões no quiz.

Durante as aulas de Informática, os grupos se reuniam para realizar as atividades de maneira colaborativa, onde discutiam e tomavam decisões sobre o quiz, tais como: layout, regras, imagens, narrativa e demais aspectos que compõem um game. Nas aulas, o papel da professora de Informática foi orientar os alunos durante a atividade, dando suporte às questões técnicas, por exemplo: pesquisa na internet, tratamento de imagens, formatação dos slides, configuração dos hiperlinks, etc.

Os jogos foram desenvolvidos de duas maneiras: o jogador tem o direito de escolher por qual disciplina iniciar a partida ou as perguntas são sequenciais, cumprindo uma ordem previamente estabelecida. Caso o jogador erre a questão, é direcionado para a mesma pergunta e só prossegue no jogo quando acertar. Outros jogos, em caso de erro, guiam o jogador para o início do quiz. Cada equipe escolhia a própria estratégia do jogo.

No jogo representado na Figura 1, o jogador é inserido em uma narrativa e guiado por um personagem. Cada disciplina tem um guardião baseado em deuses da mitologia nórdica, que é confrontado pelo jogador ao responder as perguntas. Caso erre uma questão, o personagem perde uma vida, representada por um coração azul, conforme mostrado na Figura 1(b). Quando o número de vidas chega a zero, ou seja, todos os corações ficarem pretos, o quiz é finalizado.

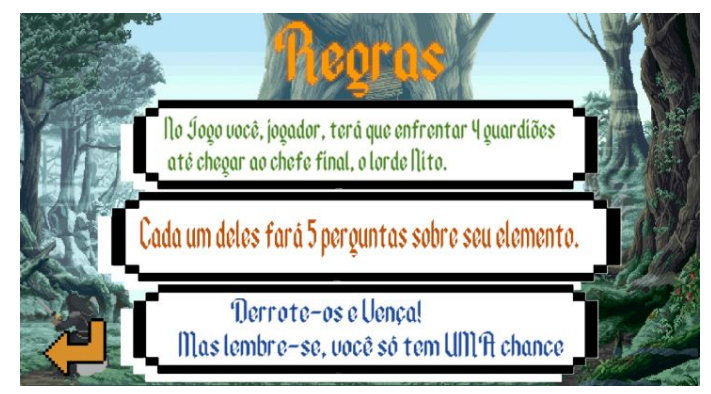

(a) Narrativa

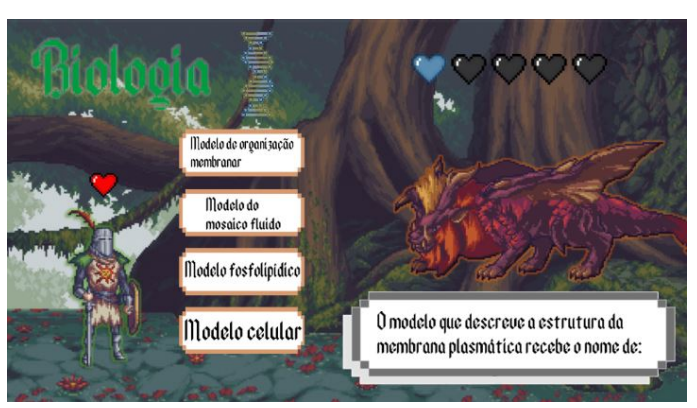

(b) Vidas

Figura 1. Jogo com narrativa e vidas 
A Figura 2 mostra exemplos de questões de disciplinas que participaram do projeto. Os discentes buscaram na internet imagens de domínio público para usar como cenário relacionando às disciplinas e criando uma interface mais amigável. Os botões com os links (regras, iniciar e respostas) foram criados pelos próprios estudantes, utilizando os recursos de desenho do editor de apresentação.

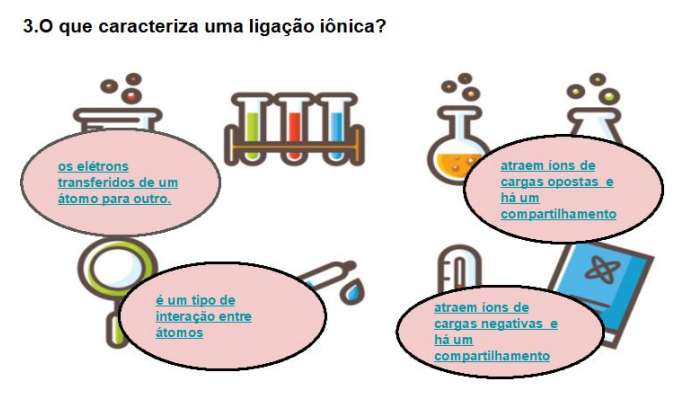

(a) Questão de Química

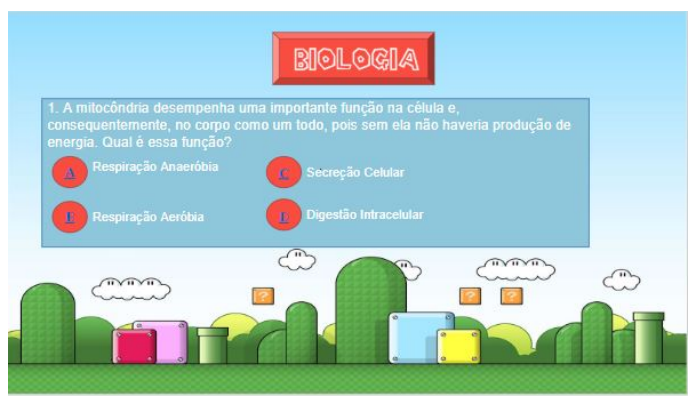

(b) Questão de Biologia

Figura 2. Exemplo de questões

\subsection{Scratch}

Durante a execução do projeto no ano de 2019, os alunos demonstraram o interesse em incrementar os quizzes, tanto na interação com o usuário quanto na pontuação.

Surgiu então a ideia de fazer novos jogos, desta vez utilizando a programação. No Scratch, as funções são separadas por cores, para facilitar a sua localização. Por exemplo, no bloco verde situam-se as operações matemáticas e lógicas, no bloco laranja encontramse as funções de controle e no azul estão as funções utilizadas para controlar o movimento dos objetos. Os blocos de programação foram desenvolvidos para se encaixarem apenas de forma que faça sentido sintaticamente.

As aulas iniciais, conforme mostrado na Tabela 2, foram dedicadas ao ensino de conceitos de programação. Após a explicação do conceito, os alunos resolviam uma lista de exercícios, para melhor compreensão do conteúdo e revisão de alguns conceitos matemáticos. Durante as aulas de elaboração do projeto, os alunos puderam aplicar os conceitos aprendidos de programação, desenvolvendo a aprendizagem colaborativa e a criatividade.

A Figura 3(a) mostra uma questão na qual o jogador tem como objetivo informar a altura do prédio utilizando conhecimentos de trigonometria. Os estudantes utilizaram personagens e cenários já disponíveis no Scratch e criaram uma narrativa em que a personagem Ana (à esquerda) desafia o personagem Eduardo (à direita) com perguntas sobre os conteúdos. $\mathrm{O}$ jogador assume o papel de Eduardo, e deve responder as questões digitando a solução na caixa de diálogo.

A Figura 3(b) apresenta uma questão sobre equação do $2^{0}$ grau. Neste quiz, há apenas um personagem e o diálogo é realizado diretamente com o jogador. O usuário deve ficar atendo ao número de tentativas, que é mostrado na tela. Quando atingir o limite de tentativas, ou seja, chegar a zero, o jogo é encerrado. 


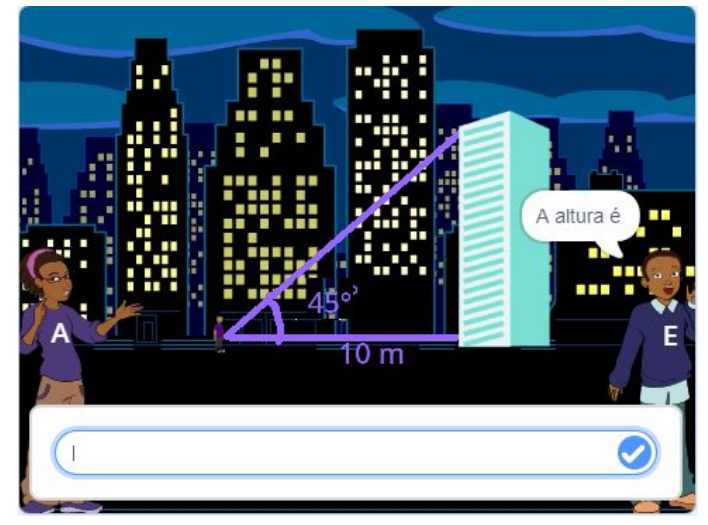

(a) Questão de Trigonometria

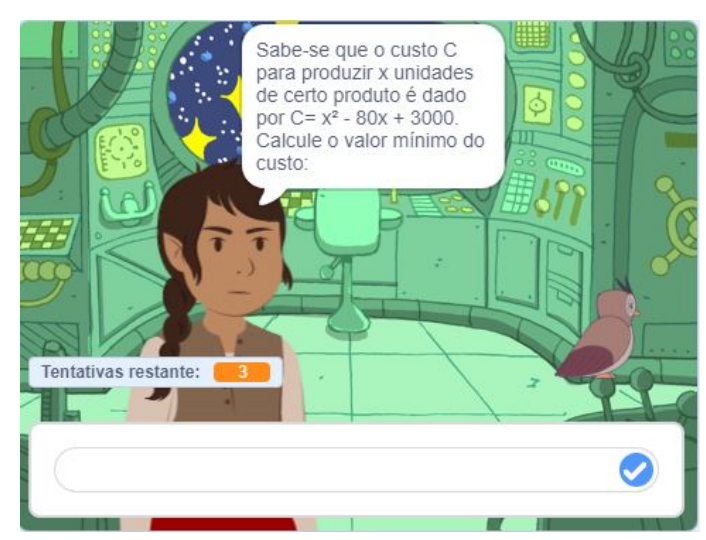

(b) Questão de Equação do $2^{0}$ grau

Figura 3. Exemplo de questões

O jogo da Figura 4 também limita o número de tentativas, porém possui o elemento surpresa das moedas. As moedas podem ser coletadas em determinados momentos do jogo, possibilitando que o jogador tenha mais chances. Quando a quantidade de moedas for zero, então o quiz é finalizado.

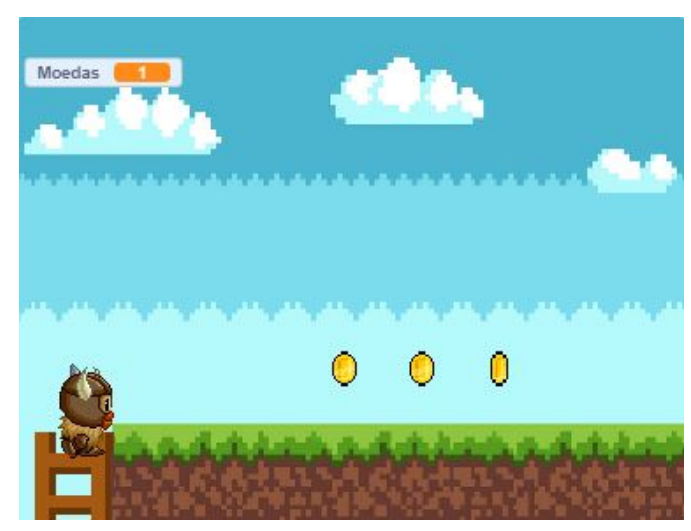

Figura 4. Coletando moedas

\subsection{Apresentação dos jogos}

Para exibição dos jogos, foi reservado um momento no auditório da escola, onde estiveram presentes todos os alunos e professores envolvidos no projeto. As apresentações foram feitas por meio de um data show, e os alunos tiveram a oportunidade de jogar os quizzes elaborados pelos colegas.

Após as apresentações, houve um momento para dialogar sobre a experiência, no qual alunos e professores tiveram a oportunidade de expor suas considerações sobre a execução do projeto e dos jogos desenvolvidos.

\subsection{Avaliação das atividades}

Como pode ser observado, esse projeto proporcionou aos alunos uma oportunidade de trazer para a sala de aula uma atividade que faz parte da sua vivência fora do espaço escolar. Como já entendiam o funcionamento do quiz, não tiveram dificuldade em desenvolver 
um. Inicialmente, não precisaram aprender uma linguagem e lógica de programação, visto que os quizzes foram criados em uma ferramenta que já sabiam utilizar, direcionando o foco para os jogos e não para a programação.

A aprendizagem aconteceu de maneira colaborativa, centrada no aluno, pois os professores tiveram o papel de orientar a atividade, auxiliando nas dificuldades que surgiam e não apenas transmitindo os conteúdos. Durante as aulas, os discentes discutiam ideias, analisavam as possíveis soluções e decidiam qual o caminho a seguir no surgimento de divergências. Assim, foi possível melhorar as relações na sala de aula, promovendo o respeito, a aceitação de uma opinião diferente, assim como uma aproximação maior com os professores.

No terceiro ano do projeto, após a criação dos quizzes no Google Apresentações, os alunos demonstraram interesse em desenvolver jogos mais aprimorados, nos quais precisassem oferecer alternativas e que o jogador informasse a resposta sem a possibilidade de apenas escolher uma mais provável. Outra necessidade que eles apontaram foi a de limitar a quantidade de tentativas, já que os jogos desenvolvidos no Google Apresentações só se encerravam depois que todas as perguntas eram respondidas, tornando a execução dos quizzes demorada.

Então, na turma de 2019, além do Google Apresentações, os alunos desenvolveram jogos também no Scratch. Foram necessárias aulas sobre conceitos básicos de programação, visto que nenhum aluno tinha experiência. Nas aulas, os exercícios envolviam conteúdos de matemática já vistos em sala, que serviram como reforço e revisão.

Após a apresentação, os alunos que desenvolveram os jogos no Google Apresentações relataram sobre a experiência, e dentre as vantagens, destacaram: uma única atividade como nota para diversas disciplinas, desenvolver o projeto em grupo, aprender a criar um jogo, a turma jogar o quiz elaborado e liberdade de criação dos elementos do jogo. A turma que desenvolveu no Scratch, acrescentou as seguintes vantagens: aprender a programar, acrescentar sons já disponíveis no Scratch sem precisar pesquisar na internet, limitar o número de tentativas, usar perguntas abertas, revisar o conteúdo de matemática e o jogo já ficar disponível na internet, facilitando o compartilhamento entre os colegas.

Como dificuldades enfrentadas, os discentes informaram sobre a complexidade de elaborar as questões e o excesso de trabalho ao configurar os hiperlinks no Google Apresentações, visto que para cada resposta, certa ou errada, deve ser configurada uma ação que leva a um outro slide. A turma que também desenvolveu os jogos no Scratch, relatou a dificuldade em colocar na prática alguns conceitos de algoritmos, mas com a prática de exercícios e o desenvolvimento do quiz, as dúvidas foram sendo resolvidas.

$\mathrm{Na}$ apresentação dos trabalhos, os quizzes elaborados pelos alunos foram jogados pela classe e nos momentos de dúvidas os professores reforçaram o conteúdo com explicações. Desta maneira, a turma teve a oportunidade de ampliar os conhecimentos neste projeto tanto no desenvolvimento dos games quanto no momento de jogar os produzidos pelos colegas.

É possível afirmar que a gamificação de conteúdos, de modo colaborativo, contribuiu significantemente no processo de aprendizagem dos educandos. Tanto na elaboração dos games, quanto ao jogar, os alunos tiveram a oportunidade de aprender sobre os 
IX Congresso Brasileiro de Informática na Educação (CBIE 2020)

Anais do XXXI Simpósio Brasileiro de Informática na Educação (SBIE 2020)

conteúdos de maneira lúdica e em colaboração com colegas e professores.

\section{Considerações finais}

Ao ingressar no Curso Técnico Integrado ao Ensino Médio em Edificações, os alunos têm sua rotina escolar totalmente alterada, visto que há um aumento significativo do número de componentes curriculares. A taxa de evasão é consideravelmente alta, pois muitos discentes não conseguem se adaptar à nova demanda de estudos.

Daí a importância da interdisciplinaridade, na qual as disciplinas relacionam seus conteúdos para aprofundar o conhecimento e incentivar a aprendizagem. Neste projeto, a disciplina de informática serviu de ligação, sendo durante suas aulas que os alunos puderam aplicar os conhecimentos adquiridos nos demais componentes curriculares. Um dos pontos positivos destacado pelos alunos foi a redução do número de exames, já que o projeto foi utilizado como avaliação em todas as disciplinas que participaram do projeto.

Por meio da gamificação, foi possível integrar os conteúdos das disciplinas envolvidas, as avaliações de aprendizagem foram reduzidas, os conceitos científicos foram aplicados de modo significativo pelos educandos. Os quizzes permitiram ainda o desenvolvimento de habilidades como: autonomia, relacionamento interpessoal e criatividade.

Faz parte da ementa de informática o editor de apresentação, sendo este usado principalmente para comunicação em seminários. Os estudantes demonstraram interesse ao descobrir que essa ferramenta poderia ser utilizada para criar quizzes que estavam habituados a jogar na internet.

A aprendizagem colaborativa foi proporcionada durante toda a execução da atividade. Os alunos foram incentivados a trabalhar em equipe, tanto na elaboração das perguntas quanto na produção do game. Ao formular as questões, alunos que tinham uma facilidade maior com o conteúdo conduziam essa etapa, sendo esses papéis trocados a depender da atividade que estava sendo realizada. Alguns alunos tinham habilidade com informática e tomaram a iniciativa na construção dos layouts e dos algoritmos, por exemplo. Assim, tiveram que debater ideias e tomar decisões em conjunto, procurando a melhor maneira de cumprir a atividade.

Outro ponto a se destacar foi o desenvolvimento da criatividade, seja pela elaboração das questões e layout, mas também pelas narrativas dos jogos. Por exemplo, no quiz apresentado na Figura 1, o jogador é levado por uma narrativa, na qual cada disciplina é defendida por um guardião, e para vencer o jogador precisa passar por todos eles, mas sem esgotar as chances. Antes das perguntas, é contada a história de cada guardião, utilizando elementos da mitologia nórdica, por meio de diálogos e simulando uma animação.

Por meio desse projeto, foi possível por em prática a metodologia de aula centrada no aluno, visto que o papel dos professores era orientar os discentes, sendo eles os responsáveis pela construção do próprio saber. No dia da apresentação, os professores intervieram no momento de dúvidas, ou para complementar os conteúdos abordados nos jogos.

Ao longo dos três anos deste projeto, foi despertado em alguns alunos o interesse por Computação. Surgiu então a ideia de desenvolver projetos de pesquisa sobre jogos educacionais. Desde 2017, já foram onze projetos desenvolvidos pelo Programa Insti- 
tucional de Bolsas de Iniciação Científica no Ensino Médio (PIBIC-EM) vinculados ao $\mathrm{CNPq}$ com tema em jogos educacionais, sendo seis aprovados esse ano. No total, dez alunos deste curso foram bolsistas nesses projetos, sendo que atualmente são quatro. Os projetos têm como foco o desenvolvimento de jogos educacionais e, atualmente, envolvem a técnica de Realidade Aumentada para auxiliar no processo de aprendizagem das disciplinas de Química, Biologia, Física e História.

Desta maneira, a principal contribuição deste trabalho foi expor como a gamificação pode ser utilizada como ferramenta para a prática da aprendizagem colaborativa, motivando os alunos e proporcionando um espaço criativo para a construção do conhecimento. Como trabalho futuro, será analisado como a linguagem Scratch, além de promover a aprendizagem colaborativa pode contribuir para o desenvolvimento do Pensamento Computacional.

\section{Referências}

Alves, R., Geglio, P. C., Moita, F., Souza, C., and Araújo, M. (2015). O quiz como recurso pedagógico no processo educacional: apresentação de um objeto de aprendizagem. XIII Congresso Internacional de Tecnologia na Educação. Pernambuco.

Bittencourt, C. S., Grassi, D., Arusievicz, F., and Tonidandel, I. (2004). Aprendizagem colaborativa apoiada por computador. RENOTE-Revista Novas Tecnologias na Educação, 2(1).

Coutinho, C. (2019). Promoção juntou ganhou: Uma experiência gamificada para o engajamento de estudantes de ensino médio. In Anais dos Workshops do Congresso Brasileiro de Informática na Educação, volume 8, page 739.

Morin, E. (2000). Os sete saberes necessários à educação do futuro. Editora Cortez.

Oliveira, L., Rosa, S., and Pimentel, A. (2019). Revisão Sistemática da Literatura: Formação de Grupos na Aprendizagem Colaborativa com Suporte Computacional. Brazilian Symposium on Computers in Education (Simpósio Brasileiro de Informática na Educação - SBIE), 30(1):1955.

Schneider, H. N. (2013). A educação na contemporaneidade: flexibilidade, comunicação e colaboração. International Journal of Knowledge Engineering and Management (IJKEM), 2(2):86-104.

Terradas, R. D. (2019). A importância da interdisciplinaridade na educação matemática. Revista da Faculdade de Educação, 14(16):95-114.

Wiener, A. and de Campos, A. (2018). Colligo app: gamificação em sala de aula. In Anais dos Workshops do Congresso Brasileiro de Informática na Educação, volume 7, page 272.

Wiener, A. and de Campos, A. (2019). Kolligo: gamificação na educação para experiência de aprendizagem mais engajadoras. In Anais dos Workshops do Congresso Brasileiro de Informática na Educação, volume 8, page 1180. 